\title{
Delta deletion 4977 in mitochondrial DNA in patients with idiopathic Parkinson's disease
}

\author{
Taravari $\mathrm{A}^{1}$, Panov $\mathrm{S}^{2}$, Petrov $\mathrm{I}^{1}$, Petrova $\mathrm{V}^{1}$, Medziti $\mathrm{F}^{1}$, Haliti $\mathrm{G}^{1}$ \\ University Clinic of Neurology, Skopje, Macedonia.
}

\begin{abstract}
Aim: To determine the presence of delta deletion 4977 in mitochondrial DNA in patients with Idiopathic Parkinson's disease (IPD).

Material and methods: This has been a prospective, clinically genetic study, lasting for whole two years. The clinical part of this study was made at the University Clinic of Neurology in Skopje, Unit for extrapyramidal diseases. The laboratory-genetic part of the study was elaborated at the Laboratory for molecular biology at the Institute for Biology, Faculty of Sciences, University "Sts. Cyril and Methodius". This study comprised a total of 32 subjects with a clinically verified diagnosis for idiopathic Parkinson's disease; 18 men and 14 women (with mean age of 52.7 years). Control group consisted of 31 randomly selected, literally healthy persons, at similar age, with similar gender distribution, and no clinical and anamnestic data for parkinsonism or similar clinical entities. Results: Objective neurologic results of all 32 investigated subjects $(100 \%)$ showed presence of rigor, tremor and bradykinesia. The difference tested between the investigated and control group, concerning the present or absent deletion and heteroplasmia, has been highly statistically significant $(p=0.001)$.

Conclusion: It could be concluded with a great statistical significance that deletion 4977 in mitochondrial genome has been registered more frequently in the group of patients with IPD (Tab. 10, Fig. 6, Ref. 36). Text in PDF www.elis.sk.

Key words: delta deletion, mitochondrial DNA, Parkinson's disease.
\end{abstract}

The term parkinsonism has been used to describe the motor characteristics in Parkinson's disease (PD), which serve for differentiation from idiopathic Parkinson's disease (IPD), and which manifest due to different clinical and pathophysiological mechanisms. In order to come to a definite diagnosis in our study, we used the Brain Bank Criteria of the United Kingdom Parkinson's Disease Society (UKPDS) (17).

IPD has a favourable clinical result when treated with dopamine agonists or Levo-dopa drugs. It appears most frequently unilaterally and has a characteristic clinical picture with generalized slowness and typical tremor $(4-6 \mathrm{~Hz})$ resembling that of money counting (22).

Essential change in IPD is the decreased dopaminergic neurotransmission in basal ganglia. Idiopathic Parkinson's disease is the most frequent type of parkinsonism, and is presented in almost $70 \%$ of patients with parkinsonism (22).

Genetic factors have an essential role in clinical manifestation of the disease; the real role of these genes will be discovered in the future with ambitious investigations aimed especially at explain-

${ }^{1}$ University Clinic of Neurology, Skopje, Macedonia, and ${ }^{2}$ Faculty of Natural Sciences, Chair for Genetics and Molecular Biology, Skopje, Macedonia.

Address for correspondence: A. Taravari, University Clinic of Neurology, Skopje, Macedonia. ing the role of molecular biology in inheritance not obeying the Mendel in IPD, as well as at our capability to use this precious knowledge to the benefit of our patients $(8,32)$.

In summary, two autosomal dominant genes ( $\alpha$-synuclein and LRRK2) and three autosomal-recessive genes (parkin, DJ-I and PINK1) are definitely associated with the inherited and early-onset form of IPD. In addition to them, there are other objective mutations such as UCHL-1, synphilin-1 and NR4A2, which perhaps are not biologically significant $(2,6,9,11,32)$.

These discoveries in the field of genetics of IPD enabled the development of two significant hypotheses for the possible pathophysiological mechanism for occurrence of parkinsonism. In short, these, possibly joinable hypotheses include:

1. Aberration in ubiquitin-proteasomal pathway ( $\alpha$-synuclein/ parkin/UCHL-I), and

2. Oxidative stress/mitochondrial dysfunction (DJ-1/PINK1) (12).

\section{Delta deletion 4977 in IPD}

Mitochondria are closed membranous organelles found in all eukaryotic cells. They are very important cell components, playing a significant role in many cell functions such as metabolism (oxidative phosphorylation), apoptosis, and aging (15). A typical eukaryote cell contains about 2,000 mitochondria which comprise approximately one-fifth (1/5th) of the total cell volume (34). They are known to be semi-autonomic organelles which have their own 
genome and own mechanisms for replication, transcription and protein synthesis (28).

Mitochondria, as cell organelles, play an important role in metabolism of eukaryote cells. One of the most important mitochondrial functions is ATP synthesis (through carbohydrate catabolism and fat oxidation), which is a process that includes a series of enzymatic complexes associated with the inner membrane, and especially with the chain of electron transportation (27). Unfavourable side product of the respiratory chain and oxidative phosphorylation is the ROC production (reactive oxidative products: oxygen anions, hydrogen peroxide and hydroxyl radicals). ROC production occurs in conditions when electrons of respiratory chain of the Crebs' cycle engage directly in oxygen reaction. It is supposed that ROC production could be increased in conditions of excessive production of electrons which could appear in case of increased energy production or disturbed activity of the respiratory chain.

Inherited mitochondrial material differs in several features from the basic genetic material in humans. There are many factors that make the difference separating the mitochondrial genetics from that of Mendel's. Some of such most outstanding factors include the presence of several copies of genetic material in one cell, differences in the basic mechanisms significant for replication and control of transcription, and inheritance of mutation diseases from one parent. Differences between both genetic systems in human cells could be an evolution rest which enables to make distinction between the functional consequences occurred from mtDNA mutations (21).

Andersson et al (1981) published the sequence and structural organization of the human mitochondrial genome. It was the first sequenced mitochondrial genome built of 16,569 base pairs (1). According to the standard model of mitochondrial inheritance, mitochondrial mtDNA is maternal inheritance (13). It is a circular molecule which encodes 13-14 of the total of 87 proteins included in the chain of electron transportation, 2 ribosomal (12C and 16C) RNA molecules (rRNA) and 22 transportation RNA molecules (tRNA) indispensable for protein synthesis.

The polyploid nature of mitochondrial genome which has many thousands of mitochondrial copies in the cell (from 1,000 to 100,000 , depending on cell type) and it increases the importance of the mitochondrial genetics, i.e. it helps in explaining the terms of homoplasmy and heteroplasmy. Homoplasmy is a term used to explain the development of identical copies of mitochondrial genome in the cell, while heteroplasmy denotes the presence of a mixture of two or more mitochondrial genotypes. These terms are especially important when mtDNA mutation is to be explained and understood as a leader of some diseases. A low level of heteroplasmic mutations in the cell has been known as microheteroplasmy and it is difficult to detect.

It is considered that a great number of diseases such as diabetes, cardiovascular diseases, lactic acidosis, specific forms of myopathies, osteoporosis, Alzheimer's and Parkinson's diseases, strokes and many others are partly caused through mitochondrial dysfunction (33).

One of the most frequent mutations appearing in mitochondrial genomes, and being connected with the process of aging and

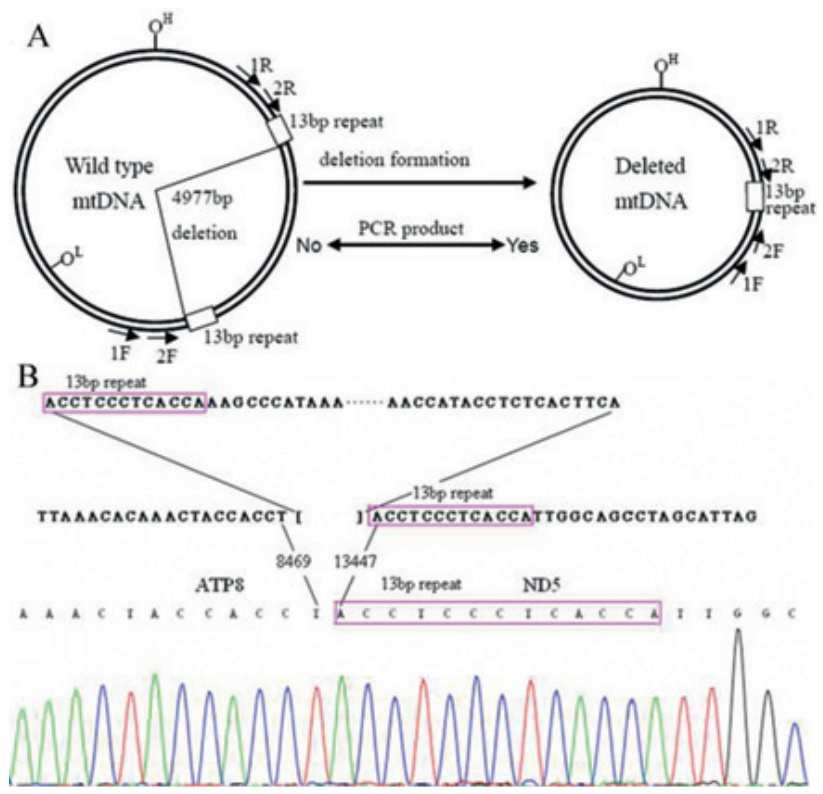

Scheme 1. Schematic distribution of deletion $\triangle \mathbf{m t D N A}^{4977}$ in human mitochondrial genome.

development of some diseases has been that of deletion $4977 \mathrm{bp}$ of mitochondrial genome $\left(\Delta \mathrm{mtDNA}^{4977)}\right.$. It is a deletion occurring between two $13 \mathrm{bp}$ direct repetitions from normal mtDNA on nucleotide positions of $8470 / 8482$ bp and $13447 / 13459$ bp $(16,31)$ (Scheme 1). This deletion, as so many others, occurs laterally on some direct or indirect repeating sequences, and because mtDNA contains many such repetitions, it can have hundreds of possible deletions (29). It is supposed that the development of mitochondrial deletions is a consequence of the sliding of erroneous chains which could have appeared during the mitochondrial replication. In that case, the deleted region will be replicated better than the normal genome, and within time, it can cause its genome to become gradually larger $(7,35)$. Symptoms of these diseases can range from light to severe, depending on the level of the accumulation of deleted molecules (30).

\section{Materials and methods}

This study comprised a total of 32 examinees with clinically verified diagnosis of idiopathic Parkinson's disease, namely 18 men and 14 women with average age of 52.7 years. The youngest examinee was 30 years old, while the oldest one was 78 . The control group consisted of 31 randomly chosen literally healthy persons at similar age, with similar gender distribution, and no clinical and anamnestic data for parkinsonism or other similar clinical entities.

This is a prospective, clinical and genetic study lasting for two years. The clinical part of this study was made at the University Clinic of Neurology, Medical School in Skopje. The laboratorygenetic part of the study was made in the Laboratory for Molecular Biology at the Institute for Biology, Faculty of Natural Sciences in Skopje. 


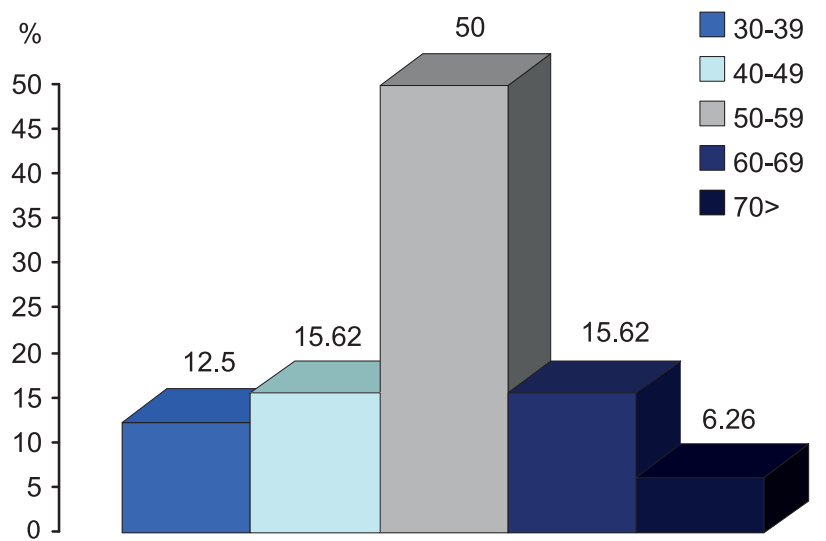

Fig. 1. Distribution of the examinees according to the age.
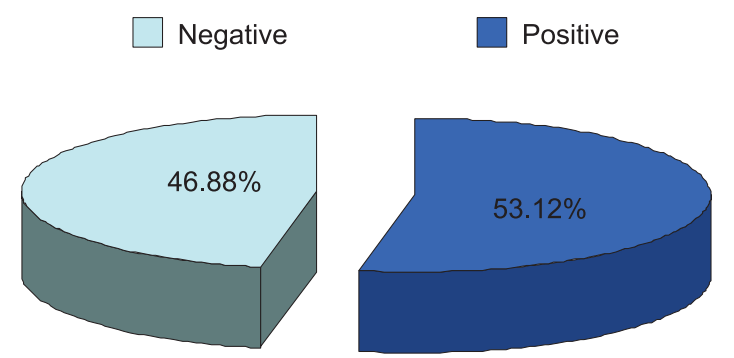

Fig. 2. Examinees' genetic anamnesis

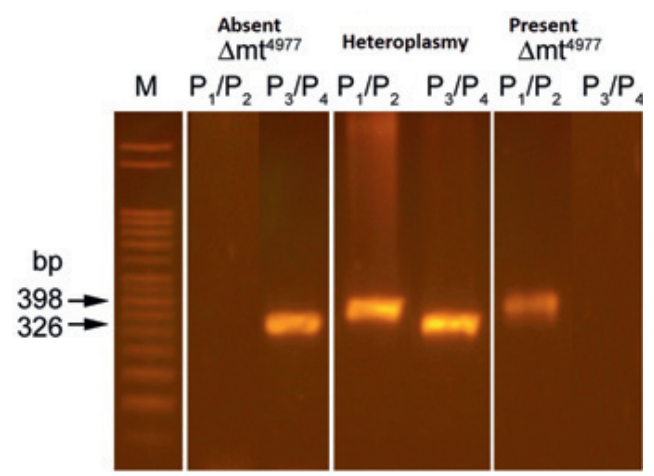

Fig. 3. Molecular detection of mt delta deletion. A composite electrophoregram of agarose gel is presented, photographed under UV-light. On M position DNA marker was applied with fragments of known length (in base pairs - bp). DNA samples are amplified with primer pairs $P 1 / P 2$ and $P 3 / P 4$. When deletion was absent, there was no deletion of the pair P1/P2, and in amplification of the pair $\mathrm{P} 3 / \mathrm{P} 4$ electrophoregram band appeared, having a length of $326 \mathrm{bp}$. Conversely, when deletion was present, amplification of the pair $\mathrm{P} 1 / \mathrm{P} 2$ resulted with a band being long $398 \mathrm{bp}$, and amplification product was absent with the pair P3/P4. In heteroplasmy, amplification products are present with both primers.

All 32 volunteers have verified IPD. At the same time, samples of venous blood were analyzed, including 2 volunteers from the families of these patients. Genetic investigations by means of molecular and genetic analyses of the patients and their family members were made, namely the detection of delta deletion mtDNA 4977.

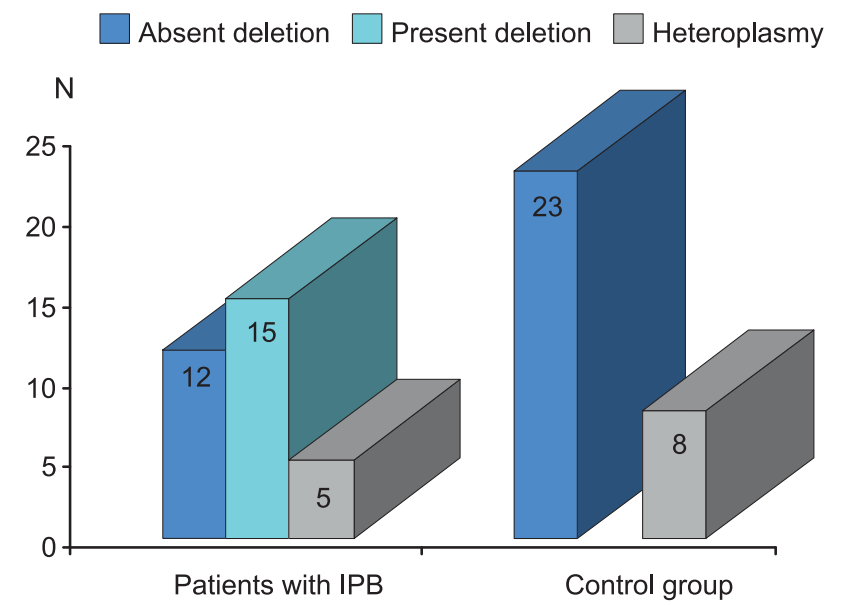

Fig. 4. Deletion ( $\triangle$ mtDNA 4977) in mitochondrial genome.

Absent deletion $\square$ Present deletion $\square$ Heteroplasmy

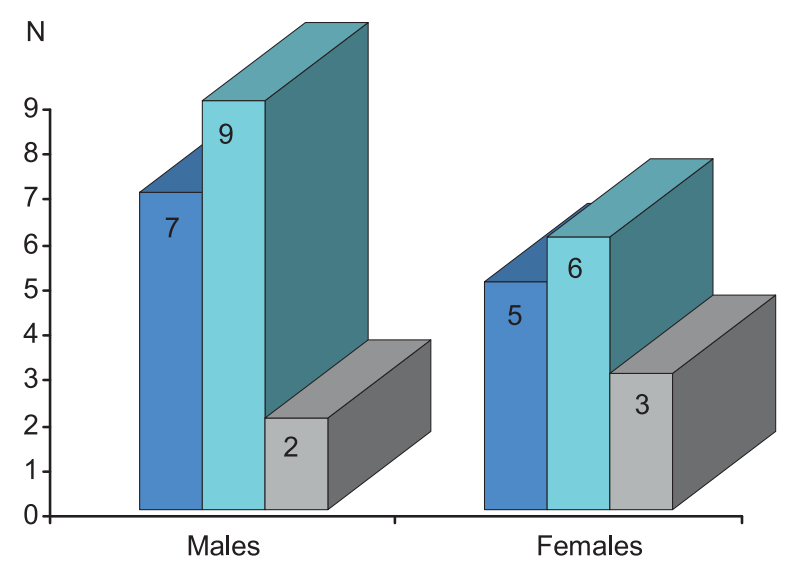

Fig. 5. Deletion ( $\triangle$ mtDNA 4977) in mitochondrial genome concerning the examinees' gender.

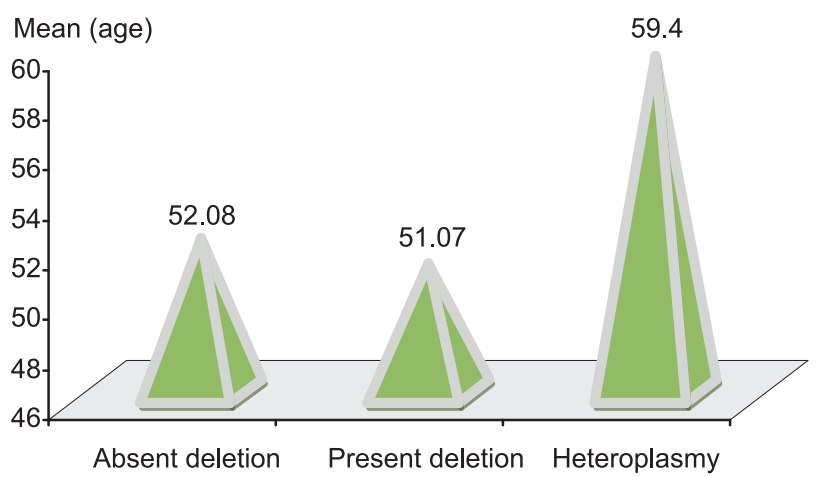

Fig. 6. Deletion ( $\triangle$ mtDNA 4977) in mitochondrial genome concerning the examinees age with IPD.

Realization of the study was approved by the Ethical Committee of the Medical School, University "Ss. Cyril and Methodius".

The examinees were diagnosed to have idiopathic Parkinson's disease (IPD). Their diagnosis was verified by means of detailed 
Table 1. Distribution of the examinees according to the age

\begin{tabular}{|c|c|c|c|}
\hline Age (years) & & $\mathrm{n}$ & $\%$ \\
\hline $30-39$ & & 4 & 12.5 \\
\hline $40-49$ & & 5 & 15.62 \\
\hline $50-59$ & & 16 & 50.0 \\
\hline $60-69$ & & 5 & 15.62 \\
\hline $70>$ & & 2 & 6.26 \\
\hline All & & 32 & 100 \\
\hline Mean $=52.75 \pm 10.3$ & Median $=50$ & $\operatorname{Min}=30$ & $\mathrm{Max}=78$ \\
\hline
\end{tabular}

Table 2. Examinees genetic anamnesis

\begin{tabular}{lcc}
\hline Genetic anamnesis & $\mathrm{n}$ & $\%$ \\
\hline Positive & 17 & 53.12 \\
Negative & 15 & 46.88 \\
All & 32 & 100 \\
\hline
\end{tabular}

Table 3. Distribution of the symptoms: rigidity, tremor and dyskinesia

\begin{tabular}{lccccccccc}
\hline Symptoms & \multicolumn{2}{c}{ Rigidity } & & \multicolumn{2}{c}{ Tremor } & & \multicolumn{2}{c}{ Dyskinesia } \\
\cline { 2 - 3 } \cline { 8 - 9 } & $\mathrm{n}$ & $\%$ & & $\mathrm{n}$ & $\%$ & & $\mathrm{n}$ & $\%$ \\
\hline Present & 32 & 100 & & 32 & 100 & & 15 & 46.88 \\
Absent & $/$ & $/$ & & $/$ & $/$ & & 17 & 53.12 \\
All & 32 & 100 & & 32 & 100 & & 32 & 100 \\
\hline
\end{tabular}

Table 4. Distribution of the symptoms: bradykinesia, reduced postural reflexes (RPR) and bradylalia

\begin{tabular}{|c|c|c|c|c|c|c|}
\hline \multirow[t]{2}{*}{ Symptoms } & \multicolumn{2}{|c|}{ Bradykinesia } & \multicolumn{2}{|c|}{ RPR } & \multicolumn{2}{|c|}{ Bradylalia } \\
\hline & $\mathrm{n}$ & $\%$ & $\mathrm{n}$ & $\%$ & $\mathrm{n}$ & $\%$ \\
\hline Present & 32 & 100 & 31 & 96.87 & 28 & 87.5 \\
\hline Absent & / & / & 1 & 3.13 & 4 & 12.5 \\
\hline All & 32 & 100 & 32 & 100 & 32 & 100 \\
\hline
\end{tabular}

Table 5. Deletion (AmtDNA 4977) in mitochondrial genome

\begin{tabular}{lcc}
\hline$\Delta$ mtDNA 4977 & Patients with IPB & Control group \\
\hline Absent deletion & $12(37.5 \%)$ & $23(74.19 \%)$ \\
Present deletion & $15(46.87 \%)$ & 0 \\
Heteroplasmy & $5(15.63 \%)$ & $8(25.81 \%)$ \\
All & 32 & 31 \\
\hline
\end{tabular}

anamnesis and detailed clinical neurologic examination while strictly obeying the Brain Bank Criteria, as well as by means of performed investigations, namely neurophysiologic investigations, brain nuclear imaging resonance, Doppler of the extracranial carotid arteries and neuropsychologic investigations.

Majority of the variants for PCR method enable their choice depending on the type of the analysis which is to be made. Beside the classical PCR reaction, for DNA deletion $\left(\Delta \mathrm{mtDNA}^{4977}\right)$, a nested PCR as well as PCR are very often used to amplify the long fragments (Long PCR).

In this study, for PCR amplification and detection of $\triangle \mathrm{mtD}$ $\mathrm{NA}^{4977}$ deletion, two pairs of primers, namely mtDNA 4977-1/2
Table 7. Deletion ( $\triangle \mathrm{mtDNA} 4977$ ) in mitochondrial genome concerning the examinees gender

\begin{tabular}{lcccc}
\hline Gender & \multicolumn{3}{c}{$\Delta$ mtDNA 4977 } & \multirow{2}{*}{ All } \\
\cline { 2 - 4 } & $\begin{array}{c}\text { Absent } \\
\text { deletion }\end{array}$ & $\begin{array}{c}\text { Present } \\
\text { deletion }\end{array}$ & Heteroplasmy & \\
\hline Male & $7(21.88 \%)$ & $9(28.13 \%)$ & $2(6.25 \%)$ & $18(56.25 \%)$ \\
Female & $5(15.63 \%)$ & $6(18.75 \%)$ & $3(9.38 \%)$ & $14(43.75 \%)$ \\
All & $12(37.50 \%)$ & $15(46.88 \%)$ & $5(15.63 \%)$ & 32 \\
\hline
\end{tabular}

Chi-square $=0.64 \mathrm{df}=2 \mathrm{p}=0.73$

(frw/rev) and mtDNA 4977-3/4 (frw/rev) (Sigma-Genosys) were used for corresponding separate detection of the mtDNA region when $\Delta \mathrm{mtDNA}^{4977}$ is absent, i.e. deletion is present.

\section{Results}

As to gender structure, the examinees were composed of 18 $(56.25 \%)$ male and $18(43.75 \%)$ female examinees. The average age of examinees was $52.7 \pm 10.3$ years. The youngest examinee was 30 years old, while the oldest one was 78 years old. The mean values of 50 years showed that $16(50 \%)$ of the examinees belonged to the age group of 50-59, even $23(71.87 \%)$ of the patients were older than 50 years (Tab. 1, Fig. 1)

Concerning the familial and genetic anamnesis, more than a half of examinees, i.e. 17 (53.1\%) proved that they had a patient with Parkinson's disease in their family (Tab. 2, Fig. 2).

Table 3 shows the distribution of neurologic symptoms of extrapyramidal origin, characteristic and typical for patients with IPD.

In all 32 examinees the objective neurologic finding showed the presence of rigor and hypertonia of extrapyramidal origin, respectively. Tremor was also present as one of the cardiologic symptoms of IPD in all 32 examinees. Dyskinesia as a symptom occurring due to long-term usage of substitution therapy (Levodopa) was registered in $15(46.9 \%)$ and absent in $17(53.1 \%)$ patients of our group with IPD.

Bradykinesia, the slowness of walking, as the main symptom among cardinal symptoms according to Brain Bank Criteria of United Kingdom Parkinson's Society for the Diagnosis of Parkinson's Disease, was present in all our examinees.

Reduced postural reflexes were positive in a dominant number of examinees, 31 (96.9\%).

Bradylalia, the speech changes (slow and monotonous speech) was recorded in $28(87.5 \%)$ examinees, while in $4(12.5 \%)$ of our patients, quite normal speech was recorded (Tab. 4).

\section{Detection of specific mitochondrial DNA 4977 delta deletion}

Molecular detection of $\mathrm{mt}$ delta deletion. A composite electrophoregram of agarose gel is presented, photographed under UV-

Table 6. Logistic Regression Analysis

\begin{tabular}{|c|c|c|c|c|c|c|c|}
\hline \multirow[t]{2}{*}{ Variable } & \multirow[t]{2}{*}{ B } & \multirow[t]{2}{*}{ Wald } & \multirow[t]{2}{*}{$\mathrm{df}$} & \multirow[t]{2}{*}{ Sig. } & \multirow[t]{2}{*}{$\operatorname{Exp}(B)$} & \multicolumn{2}{|c|}{$95,0 \% \mathrm{CL}$ for $(\mathrm{B})$} \\
\hline & & & & & & Lower & Upper \\
\hline Age & 0.009 & 0.109 & 1 & 0.741 & 1.009 & 0.957 & 1.063 \\
\hline$\Delta \mathrm{mt} 4977$ & 1.590 & 8.191 & 1 & 0.004 & 4.902 & 1.65 & 14.559 \\
\hline Constant & -1.128 & 0.572 & 1 & 0.45 & 0.324 & & \\
\hline
\end{tabular}


Table 8. Deletion ( $\triangle$ mtDNA 4977) in mitochondrial genome concerning the ethnic nationality of the examinees

\begin{tabular}{lccc}
\hline Nationality & \multicolumn{3}{c}{ All } \\
\cline { 2 - 4 } & Absent deletion & Present deletion & Heteroplasmy \\
\hline Macedonian & $4(12.50 \%)$ & $8(25.00 \%)$ & 0 \\
Albanian & $6(18.75 \%)$ & $4(12.50 \%)$ & $4(12.50 \%)$ \\
Turkish & $2(6.25 \%)$ & $3(9.38 \%)$ & $1(3.13 \%)$ \\
All & $12(37.50 \%)$ & $15(46.88 \%)$ & $5(43.75 \%)$ \\
\hline
\end{tabular}

Chi-square $=5.59 \mathrm{df}=4 \mathrm{p}=0.23$

Table 9. Deletion ( $\Delta$ mtDNA 4977) in mitochondrial genome concerning the examinees' age with IPD

\begin{tabular}{lccc}
\hline$\Delta$ mtDNA 4977 & $\mathrm{n}$ & Age & SD \\
\hline Absent deletion & 12 & 52.083 & 11.62 \\
Present deletion & 15 & 51.067 & 7.56 \\
Heteroplasmy & 5 & 59.40 & 13.72 \\
\hline
\end{tabular}

Analysis of Variance $\mathrm{F}=1.28 \mathrm{p}=0.29$

light. On M position, DNA marker was applied with fragments of known length (in base pairs - bp). DNA samples are amplified with primer pairs $\mathrm{P} 1 / \mathrm{P} 2$ and $\mathrm{P} 3 / \mathrm{P} 4$. When deletion was absent, there was no deletion of the pair $\mathrm{P} 1 / \mathrm{P} 2$, and in amplification of the pair $\mathrm{P} 3 / \mathrm{P} 4$, an electrophoregram band appeared in length of $326 \mathrm{bp}$. Conversely, when deletion was present, amplification of the pair $\mathrm{P} 1 / \mathrm{P} 2$ resulted with a band in length of $398 \mathrm{bp}$, and amplification product was absent with the pair P3/P4. In heteroplasmy, amplification products are present with both primers (Fig. 3).

In this of part of the examination, the results relating to the detection of specific mitochondrial DMA 4977 delta deletion ( $\Delta$ mtDNA 4977 deletion) are present. For carrying out this objective, 32 examinees were analyzed and diagnosed with IPD while $31(46.9 \%)$ conditionally healthy examinees constituted our control group.

In the study group of patients, the deletion of mitochondrial genome has been registered in $15(46.9 \%)$ of the examinees constituting our control group.

This deletion was detected only in 8 (25.8\%) examinees of the control group. The differences between the examinees and control group tested in relation to presence or absence of deletion or heteroplasmy was highly statistically significant $(\mathrm{p}=0.001)$. Deletion in mitochondrial genome has been registered highly significantly more often in the group of patients with IPD (Tab. 5, Fig. 4).

In order to quantify, or in fact to measure the relationship between the deletion in the mitochondrial genome and idiopathic Parkinson's disease, we performed Logistic Regression Analysis (Binary Logistic Regression). Results from this analysis are shown in Table 6.

As opposed to recent investigations showing that with age, the appearance of deletion $\Delta$ mtDNA 4977 in mitochondrial genome increases, our investigation showed that the examinees' age did not prove to be a significant factor in relation to the latter deletion $(\mathrm{ExpB}=1.01$ 95\% CL 0.957-1.063).

As to the deletion 4799 of the mitochondrial genome, it could be proved to represent an independently significant factor, i.e. the examinees with a verified deletion of mitochondrial genome had a 4.9-fold greater chance of developing idiopathic Parkinson's disease compared to the examinees without deletion $(\mathrm{ExpB}=4.9$ 95\% CL 1.65-14.56).

Deletion of mitochondrial genome was present in 9 (28.1 $\%)$ male and $6(18.7 \%)$ female examinees, while not detected in $7(21.9 \%)$ male and $5(15.6 \%)$ female examinees. Heteroplasmy was almost equally present in examinees of both genders (2 vs 3).

The differences tested between the groups with deletion, and those without deletion and with heteroplasmy in relation to their gender was statistically non-significant $(\mathrm{p}>0.05)$.

The development of deletion in the mitochondrial genome in idiopathic Parkinson's disease, did not depend significantly on gender (Tab. 7, Fig. 5).

Statistically significant differences in ethnic nationality of examinees with deletion of mitochondrial genome, and those without deletion and with heteroplasmy $(\mathrm{p}>0.05)$ were not registered. This statistical comment was due to the difference tested in the distribution presented in Table 8. It can be noted that deletion of mitochondrial genome was present in $8(25 \%)$ Macedonians, 4 (12.5\%) Albanians, and 3 (9.4) Turks, while heteroplasmy was found in $4(12.5 \%)$ examinees of Albanian nationality and 1 examinee of Turkish ethnic community.

The average age of examinees in group with deletion of mitochondrial genome was $51.1 \pm 7.6$ years, the age of examinees without deletion was in range of $52.1 \pm 11.6$ years, while the average age of examinees with heteroplasmy was the greatest, namely $59.4 \pm 13.7$ years. The difference in average age of the examinees with deletion and those without deletion and with heteroplasmy was statistically non-significant ( $p>0.05$ ) (Tab. 9, Fig. 6).

Deletion of mitochondrial genome was present in $9(28.1 \%)$ examinees with positive familial anamnesis for Parkinson's disease and $6(18.7 \%)$ with negative genetic anamnesis, while the deletion

Table 10. Deletion (AmtDNA 4977) in mitochondrial genome concerning the positive genetic anamnesis for Parkinson's disease

\begin{tabular}{lccc}
\hline Genetic anamnesis & \multicolumn{3}{c}{ All } \\
\cline { 2 - 3 } & Absent deletion & Present deletion & Heteroplasmy \\
\hline Positive & $5(15.63 \%)$ & $9(28.13 \%)$ & $3(9.38 \%)$ \\
Negative & $7(21.88 \%)$ & $6(18.75 \%)$ & $2(6.25 \%)$ \\
All & $12(37.50 \%)$ & $15(46.88 \%)$ & $5(15.63 \%)$ \\
\hline
\end{tabular}

Chi-square $=1.01 \mathrm{df}=2 \mathrm{p}=0.6$ 
was not present in $5(15.6 \%)$ examinees with positive and 7 (21.9 $\%$ ) with negative familial anamneses. Statistically significant difference $(\mathrm{p}>0.05)$ among the groups with deletion and with heteroplas$\mathrm{my}$ in the mitochondrial genome in relation to presence or absence of Parkinson's disease in the family was not registered (Table 10).

\section{Discussion}

Idiopathic Parkinson's disease has been approximately equally present in both genders, with a discretely greater presentation in male gender. Our study showed that the gender distribution for 32 patients with clinically verified diagnosis for idiopathic Parkinson's disease (IPD) in accord with Brain Bank Criteria yielded $18(56.25 \%)$ men and $14(43.75 \%)$ women. In most studies, as in those of Haaxma et al (2007), Lyons et al (2009) and Linder et a. (2010) performed in various time periods and on various populations, the results were similar to those in our study $(14,20,24)$.

In our study the mean age of examinees was 52.7 years. The youngest examinee was only 30 years, the oldest one was 78 . The mean age with the values of 50 years showed that $16(50 \%)$ of examinees belonged to the age group of 50-59 years, and even 23 $(71.87 \%)$ of examinees were older than 50 years.

As to the mean onset of idiopathic Parkinson's disease, the analysed papers indicate domination of those with the mean onset in the beginning of the sixth decade of life $(3,23,36)$.

In their epidemiologic study performed in Norway on 554 patients with IPD, Alves et al (2009), among others, stated that the mean age at the onset of IPD symptom manifestation was 54.3 years which was compatible with the average age of our 32 examinees (3).

In their 10-year analysis, Lopez IC et al (2010) have practically started to examine 64 cases of de novo IPD being treated with Levodopa, followed-up and examined every six months within a period of 10 years. The analysis of all symptoms and signs was made with UPDRS, starting with motor fluctuations, freezing phenomenon, postural reflexes and dyskinesia. By this paper, progression of all IPD symptoms was followed up within a period of 10 years, in their regular follow-up and regular correction of therapy depending on clinical picture. There was a statistically significant difference in progression of symptoms between patients who manifested the disease at younger age and those who developed the first symptoms at a more advanced age (18).

Ivy N. Miller and Golomb AC (2010) made an interesting, clinico-epidemiological study, in which it was stated that the disease was manifested approximately equally in both genders, however definitively some symptoms appeared more frequently in female patients while the others were more frequent in male patients. Motor symptoms occurring as a result of decreased function of the dopaminergic system, i.e. those which we investigated dominantly, dominated among men, whereas women dominantly develop only rigidity out of motor symptoms and non-motor signs. It is supposed that some still unknown hormonal mechanisms had most probably some influence on such gender differences in manifestation (19).

In the study group of patients, deletion of the mitochondrial genome was registered in 15 (46.9\%) examinees, while 5 of them had heteroplasmy.
Parihar MS et al (2008) made a very interesting paper with 274 patients who were diagnosed with IPD after strict criteria. Similarly to our study, genetic investigations for many genes were made, including alpha synuclein, while more investigations were performed for mitochondrial DNA. In two patients, mutations of LPPK 2 gene were found, mutation of alpha-sy; nuclein gene was found in none, while in $70 \%$ of the patients, delta deletion 4977 of mtDNA was found to be present. These results are quite identical with the findings in our study (25).

Charles Arthur et al (2009) investigated the premise that IPD, in fact its sporadic form, was due to disturbance in the function of enzyme systems in mitochondria. Among their examinees, they therefore investigated several potential mutations of the mitochondrial genome, including the deletion 4977. The authors came to a conclusion that there was a disturbance in the enzyme complex 1-4 in mitochondria, while in the sporadic form of IPD they did not succeed in finding a particular mitochondrial mutation which was specific only for IPD. They also concluded that the presence of delta deletion of mtDNA was very frequent in this disease, and it was statistically significantly more present in the older group of patients with sporadic form of IPD (5).

Reeve et al (2008) made a very important and interesting study dealing with delta deletion of 4977 of mtDNA. Several types of mitochondrial deletion were investigated in separate cells of substantia nigra in three groups of examinees, namely in control group, patients with IPD, and patients with other forms of parkinsonism. The authors found out 89 types of different deletions of mitochondrial DNA, among which was also delta deletion 4977. They did not succeed in finding a statistically significant presence of a definite type of deletion in some of the special types of PD (26).

\section{Conclusion}

It could be stated, with great statistical significance, that deletion in mitochondrial genome was more frequently registered in the group suffering from IPD. It was present in $62.5 \%$ of our examinees with IPD, while in the control group this delta deletion 4977 of mtDNA was present only in $25.8 \%$ of examinees. The difference tested between the examined and control group as to the presence of deletion, and its absence and heteroplasmy was highly statistically significant ( $\mathrm{p}=0.001$ ).

As opposed to recent investigations showing that with age, the appearance of deletion $\Delta$ mtDNA 4977 in mitochondrial genome increases, our investigation showed that the examinees' age did not prove to be a significant factor in relation to the latter deletion $(\mathrm{ExpB}=1.01$ 95\% CL 0.957-1.063).

The deletion 4977 of mitochondrial genome has been proved to be an independently significant factor, i.e. the examinees with verified deletion of mitochondrial genome had a 4.9-fold greater chance of developing idiopathic Parkinson's disease when compared to examinees without the deletion ( $\mathrm{ExpB}=4.995 \% \mathrm{CL} 1.65-14.56)$.

The examinees' mean age in group with deletion in mitochondrial genome was $51.1 \pm 7.6$ years, the examinees without deletion had the mean age of $52.1 \pm 11.6$ years, while the mean age of examinees with heteroplasmy was the greatest, namely in range of 
$59.4 \pm 13.7$ years. The difference in mean age of examinees with deletion, without deletion, and those with heteroplasmy was statistically non-significant $(\mathrm{p}>0.05)$.

\section{References}

1. Abnet CC, Huppi K, Carrera A, Armistead D, McKenney K, Hu N, Tang ZZ, Taylor RR, Dawsey SM. Control region mutations and the "common deletion" are frequent in the mitochondrial DNA of patients with esophageal squamous cell carcinoma. BMC Cancer 2004; 4: 30-36.

2. Aharon-Peretz J, Rosenbaum H, Gershoni-Baruch R. Mutations in the glucocerebrosidase gene and Parkinson's disease in Ashkenazi Jews. New Engl J Med 2004; 351: 1972-1977.

3. Alves G, Muller B,Herlofson K. Incidence of Parkinson's disease in Norway. The Norwegian ParkWest study. J Neurol Neurosurg Psychiatry 2009; 80: 851-857.

4. Bonifati V, Rizzu P, van Baren MJ et al. Mutations in the DJ-1 gene associated with autosomal recessive early-onset parkinsonism. Science 2003; 299: 256-259.

5. Arthur CR, Morton SL, Dunham LD, Keeney PM, Bennett JP. Parkinson's disease brain mitochondria have impaired respirasome assembly, age-related increases in distribution of oxidative damage to mtDNA and no differences in heteroplasmic mtDNA mutation abundance. Mol Neurodegener 2009; 4 (37): 1326-1324.

6. Clark LN, Ross BM, Wang Y, Mejia-Santana $\mathbf{H}$ et al. Mutations in the glucocerebrosidase gene are associated with early-onset Parkinson disease. Neurology 2007; 69: 1270-1277.

7. Cortopassi GA, Shibata D, Soong NW, Arnheim N. A pattern of accumulation of a somatic deletion of mitochondrial DNA in aging human tissues. Proc Natl Acad Sci USA 1992; 89: 7370-7374.

8. Dawson TM, Dawson VL. Molecular pathways of neurodegeneration in Parkinson's disease. Science 2003; 302: 819-822.

9. Di Fonzo A, Rohe CF, Ferreira J et al. A frequent LRRK2 gene mutation associated with autosomal dominant Parkinson's disease. Lancet 2005; 365: 412-415.

10. Esposito LA, Melov S, Panov A. Mitochondrial disease in mouse results in increased oxidative stress. Proc Natl Acad Sci USA 1999; 96: 4820-4825.

11. Funayama M, Hasegawa K, Kowa H, Saito M, Tsuji S, Obata F. A new locus for Parkinson's disease (PARK8) maps to chromosome 12p11.2-q13.1. Ann Neurol 2002; 51: 296-301.

12. Galvan A, Wichmann T. Pathophysiology of parkinsonism. Clin Neurophysiol 2008; 119: 1459-1474.

13. Giles RE, Blanc H, Cann HM, Wallance DC. Maternal inheritance of human mitochondrial DNA Proc. Natl Acad Sci USA 1980; 77: 6715-6719.

14. Haaxma CA, Bloem BR, Borm GF et al. Gender differences in Parkinson's disease. J Neurol Neurosurg Psychiat 2007; 78: 819-824.

15. Henze K, Martin W. Evolutionary biology: Essence of mitochondria. Nature 2003; 426: 127-128.

16. Holt IJ, Harding AE, Morgan-Hughes JA. Deletions of mitochondrial DNA in patients with mitochondrial myopathies. Nature1988; 331 : 717-719.

17. Hughes AJ, Daniel SE, Kilford L, Lees AJ. Accuracy of clinical diagnosis of idiopathic Parkinson's disease. A clinico-pathological study of 100 cases. JNNP 1992; 55: 181-184.
18. López IC, García Ruiz PJ, Vázquez Fernández del Pozo S, Sánchez Bernardos V. Motor complications in Parkinson's disease: Ten year follow-up study. Mov Disord 2010; 25 (16): 2735-2739.

19. Miller IN, Cronin-Golomb A. Gender differences in Parkinson's disease: Clinical characteristics and cognition. Mov Disord 2010; 25 (16): 2695-2703.

20. Linder J, Stenlund H, Forsgren L. Incidence of Parkinson's disease and parkinsonism in northern Sweden: A population-based study. Mov Disord 2010; 25 (3): 341-348.

21. Lang BF, Gray MW, Burger G. Mitochondriale genome evolution and the origin of eucariotes. Annu Rev Genet 1999; 33: 351-397.

22. Lees AJ, Hardy J, Revesz T. Parkinson's disease. Lancet 2009; 373: 2055-2066.

23. Levy G. The relationship of Parkinson disease with aging. Arch Neurol 2007; 64: 1242-1246.

24. Lyons KS, Steward BJ, Archbold PG, Carter JH. Optimism, pessimism, mutuality and gender: predicting 10-year role strain in Parkinson's disease spouses. Gerontol 2009; 49: 378-387.

25. Parihar MS, Parihar A, Fujita M, Hashimoto M, Ghafourifar $P$. Mitochondrial association of alpha-synuclein causes oxidative stress. Cell Mol Life Sci 2008; 65: 1272-1284.

26. Reeve AK, Krishnan KJ, Elson JL, Morris CM, Bender A, Lightowlers RN, Tumbull DM. Nature of mitochondrial DNA deletions in substantia nigra neurons. Am J Mum Genet 2008; 82 (1): 228-235.

27. Rotig A, Munnich A. Genetic features of mitochondrial respiratory chain disorders. J Am Soc Nephrol 2003; 14: 2995-3007.

28. Saccone C, Gissi C, Lanave C, Larizza A, Pesole G, Reyes A. Evolution of the mitochondrial genetic system: an overview. Gene 2000; 261: 153-159.

29. Samuels DC, Schon EA, Chinnery PF. Two direct repets cause most human mtDNA deletions. Trends Genet 2004; 20: 393-398.

30. Shenkar R, Navidi W, Tavaré S, Dang MH, Chomy A, Attardi G, Cortopassi G, Arnheim N. The mutation rate of the human mtDNA deletion mtDNA ${ }^{4977}$. Am J Hum Genet 1996; 59: 772-780.

31. Shoffner JM, Lott MT, Voljavec AS, Soueidan SA, Costigan DA, Wallace DC. Spontaneus Kearns-Sayre/chronic progressive external ophtalmoplegia plus syndrome associated with a mitochondrial DNA deletion: A slip-replication model and metabolic therapy. Proc Natl Acad Sci USA 1989; 86: 7952-7956.

32. Shushant J, Nicholas WW, Daniel GH. Molecular genetic pathways in Parkinson's disease. Clin Sci 2005; 109: 355-364.

33. Tatton WG, Olanow CW. Apoptosis in neurodegenerative diseases: the role of mitochondria. Biochim Biophys Acta 1999; 1410: 195-213.

34. Voet D, Voet JG, Pratt WC. Fundamentals of Biochemistry, 2nd Edition. John Wiley and Sons, 2006.

35. Wallace DC. Mitochondrial DNA sequence variation in human evolution and disease. Proc Nat Acad Sci USA 1994; 91: 8739-8746.

36. Wermuth L, Bech S, Petersen MS, Joensen P, Weihe P, Grandjean P. Prevalence and incidence of Parkinson's disease in The Faroe Islands. Acta Neurol Scand 2008; 118: 126-131.

Received March 9, 2012. Accepted April 13, 2012. 